\title{
A Psychosexual Needs Assessment of Patients Attending Five East London Sexual Health Clinics
}

\author{
Aiys ha Malik, Justin Grayer, \& S tuart Gibs on \\ Ambrose King Centre, Barts Health NHS Trust, London, U.K.
}

\section{Introduction}

- Sexual health is a national priority ${ }^{1,2}$. Services have placed emphasis on STI identification, treatment and adolescent pregnancies, to the exclusion of commonly experienced psychosexual difficulties.

- In a replication and extension of two earlier needs assessments within our service ${ }^{3,4}$ this study sought to establish the prevalence and range of psychosexual difficulties experienced by patients attending our clinics.

\section{Method}

- Questionnaires were disseminated to all patients attending five sexual health services in East London over a one week period.

- Patients were asked to endorse their self-report experience of:

- current psychosexual difficulties

- associated distress

- associated functional impairment

- causal attributions

- current support

- service-preferences

- 934 patients responded.

\section{Participants}

Age

Gender

Identity

Ethnicity

Sexual

Orientation $14-74$ years. $\mu=29.4$ years(SD=8.5) Women (61.4\%)*, Men (38.2\%), Prefer not to say $(0.3 \%)$, Other $(0.1 \%)$

White (54.8\%)*, Black/Black British (19.0\%), Asian/Asian British (11.8\%), Mixed Race (11.0\%), Chinese \& Other (3.4\%)

Heterosexual (85.5\%)*, Gay Man (5.6\%), Bisexual (5.5\%), Prefer not to say (2.9\%), Gay Woman (0.3\%),Other (0.1\%)

Relationship Single (49.1\%)*, Non-Cohabiting Partner Status (29.3\%), Co-Habiting Partner/Civil/Married (16.8\%), Prefer Not to Say (3.4\%), Divorced $(0.8 \%)$, Other $(0.4 \%)$, Widowed $(0.2 \%)$

$*_{p}<.05$

\section{References}

1 National Institute of Clinical Excellence (NICE). (2007). One-to-one interventions to reduce the transmission of sexually transmitted infections (STIS) including HIV, and to reduce the rate of under 18 conceptions, especially among vulnerable and at risk groups: Implementation advice.

2 MEDFASH. (2008). London sexual health needs and service mapping. London: Author. 3 Shepherd, L., Heke, S., \& O'Donovan, A. (2009). Sexual problems in two inner city London sexual health centres: prevalence, attributions and need for psychosexual services. Sexual and Relationship Therapy, 24(3-4), 249-260.

4 Shepherd, L., Heke, S., Sarner, L., \& O'Donovan, A. (2010). Are UK services meeting the need of patients with sexual problems and where should psychosexual services be provided? Sexual and Relationship Therapy, 25(1), 29-36.

\section{Results}

- $31.1 \%$ reported a current psychosexual difficulty.

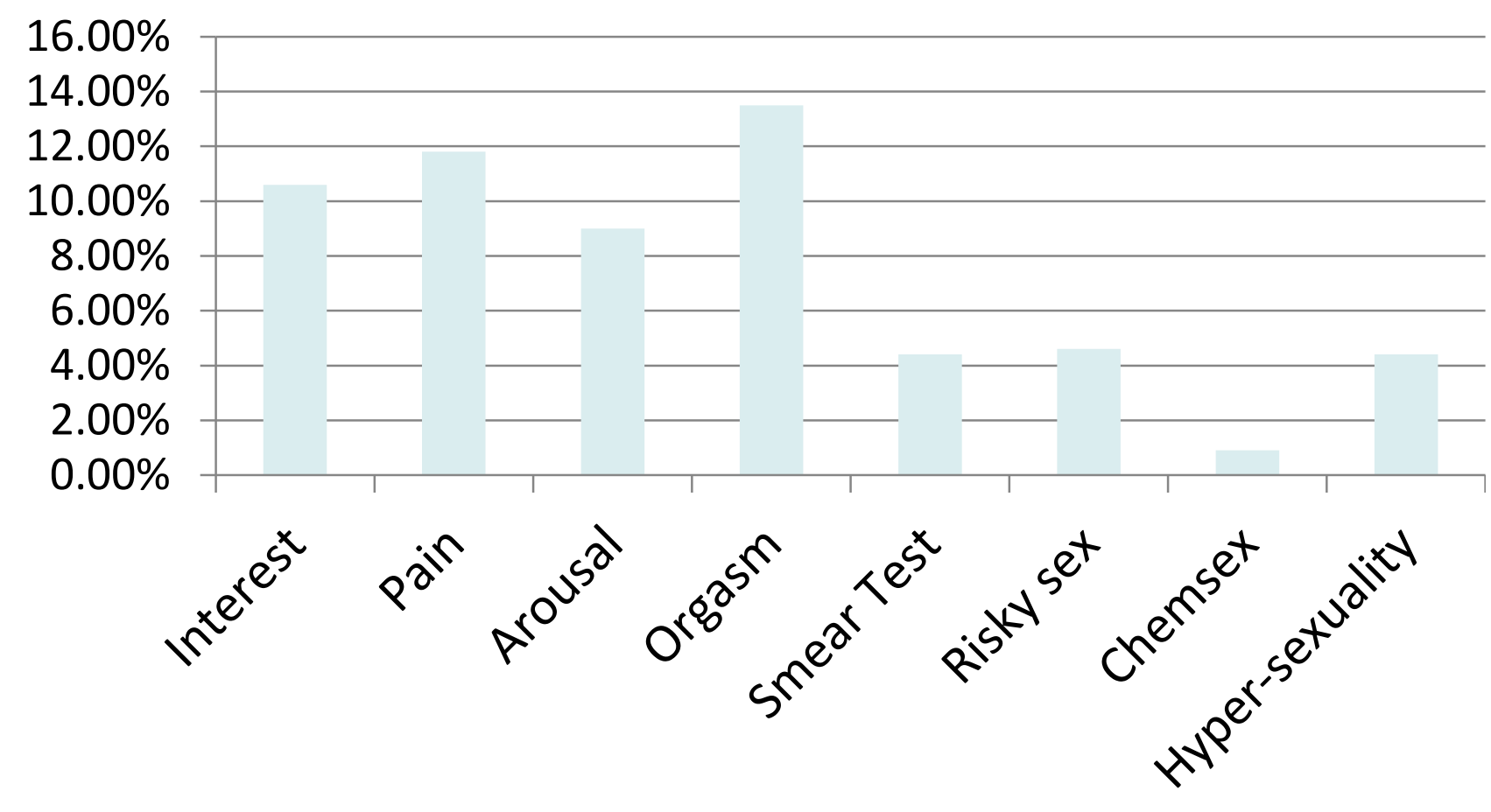

\section{Summary of Key Results}

Psychosexual Most common difficulty across all genders Difficulty was orgasm (including anorgasmia, delayed and premature ejaculation). More women reported difficulties with sexual pain (including smear test) whereas men were most likely to report difficulties with hypersexuality (including porn addiction), $\left(X s^{2}=11.3-25.2, p s<.001\right)$.

Associated

75-91.4\% report being distressed by their Distress psychosexual difficulty; men and women equally distressed (Us $=2.0-569.0, \mathrm{ps}>.05$ )

Associated

Men reported worse functional

Functional impairment $(U=1862.0, z=2.3, p=.02)$

Impairment

Causal

Attributions

Emotions/feelings attributed as most likely cause $(21.1 \%)$; equal for men and women

\section{Current $\quad$ For the majority of difficulties up to $9.1 \%$ \\ Support report receiving current professional support}

Service

Preferences

Individual Psychological Therapy (55.8\%) and Medication (56.5\%). 75.3\% want to be supported at a sexual health clinic versus GP, community, or e-medicine.

\section{Conclusion}

- $\quad$ Patients are distressed and the majority attribute psychological causes above physical causes.

- $\quad$ Patients' needs are not being met across psychosexual difficulties and male patients may have higher needs.

- Patients want to be seen in our clinics and are interested in psychological interventions and medication. 